\title{
El Cortijo del Ahorcado (Baeza, Jaén): estudio de los restos arquitectónicos de época ibérica
}

\author{
M. ${ }^{a}$ Rosario lucas Pellicer * \\ ENCARNACIÓN RUANO RUIZ **
}

Las investigaciones dedicadas en los últimos años a la arqueología del mundo ibérico han contribuido notablemente a ampliar los conocimientos sobre la arquitectura funeraria y sobre los relieves y esculturas vinculados a excepcionales monumentos erigidos en honor a los difuntos. La publicación de M. Almagro Gorbea Arquitectura y Sociedad en la Cultura Ibérica, aparecida en 1983, es, junto con otros trabajos más recientes, buena prueba de los logros alcanzados. Basta contrastar las actuales teorias y la documentación hoy disponible con la síntesis que sobre arte ibérico trazara Garcia y Bellido en 1953, para hacernos una idea cabal del progreso alcanzado en los últimos años.

No obstante, todavia falta por explicar la función y disposición de numerosos fragmentos arquitéctonicos decorados $o$ no, que se hallan dispersos en museos y colecciones privadas ( $E$. Ruano, 1981 a y $b$; 1983). Es obvio que existen lagunas y que sabemos muy poco sobre la arquitectura; por ello hemos creido oportuno volver a estudiar la columna que remata en el conocido "capitel» del Cortijo del Ahorcado (Baeza, Jaén), expuesta en la Sala de Arte Ibérico del Museo Arqueológico Nacional, ya que su morfologia y posible función se apartan de las hipótesis formuladas sobre los monumentos arquitectónicos exhumados en los últimos años.

* Universidad Autónoma de Madrid.

** Asociación Española de Amigos de la Arqueología. 
Nuestra intención, en principio, fue la de comprobar ${ }^{1}$ todos los restos arquitectónicos atribuidos al mundo ibérico que, procedentes del mismo lugar, ingresaron conjuntamente en el Museo Arqueológico Nacional. Sólo ha sido posible estudiar directamente la pieza mencionada, si bien, con las lógicas reservas impuestas por la no revisión de todos los fragmentos, se juzga conveniente no omitir los datos que a través de la bibliografía se pueden recabar.

\section{HISTORIOGRAFIA}

Los fragmentos arquitectónicos procedentes del Cortijo del Ahorcado y atribuidos a época ibérica, ingresaron en el Museo Arqueológico Nacional en 1920. Sobre las circunstancias del hallazgo solamente contamos con las referencias de J. R. Mélida: fueron descubiertos casualmente por un particular en 1916. La noticia llegó hasta $\mathrm{H}$. Sandars quien la trasmitió a J. R. Mélida, Director del Museo Arqueológico Nacional. Este arqueólogo se trasladó al lugar comprobando que los restos estaban "cerca de las ruinas de un edificio grande que por su disposición y detalle parece haber sido de unas termas romanas" (Mélida, 1923, págs. 8-10). No tuvo fortuna en sus intentos de compra si bien, en 1920, H. Sandars logró adquirir las piezas que ese mismo año donó al Museo, formando parte de un lote de capiteles, basas y columnas procedentes del mismo Cortijo.

Mélida catalogó como romano parte del conjunto y consideró ibéricas las piezas que aquí estudiamos (lám. I y fig. 1: 2 y 4) ya tanto la morfología como la decoración delataban la mano de un artista indígena y, en su opinión, habian sido reutilizadas en el edificio romano.

En la citada publicación describe todas las piezas ibéricas consideradas como capiteles, así como el fuste que encaja en uno de ellos, e ilustra el artículo con la fotografía de la columna completa.

A. Garcia y Bellido en su monografía La Arquitectura entre los Iberos (1945, págs. 93-96), repite sucintamente los datos proporcionados por Mélida y denomina "cúbico» al capitel encajado en la columna (el exhibido en la sala), calificación que ha hecho fortuna en la bibliografía.

- La remodelación de los depósitos del Museo Arqueológico Nacional ha impedido estudiar directamente las piezas 2 y 3 . 


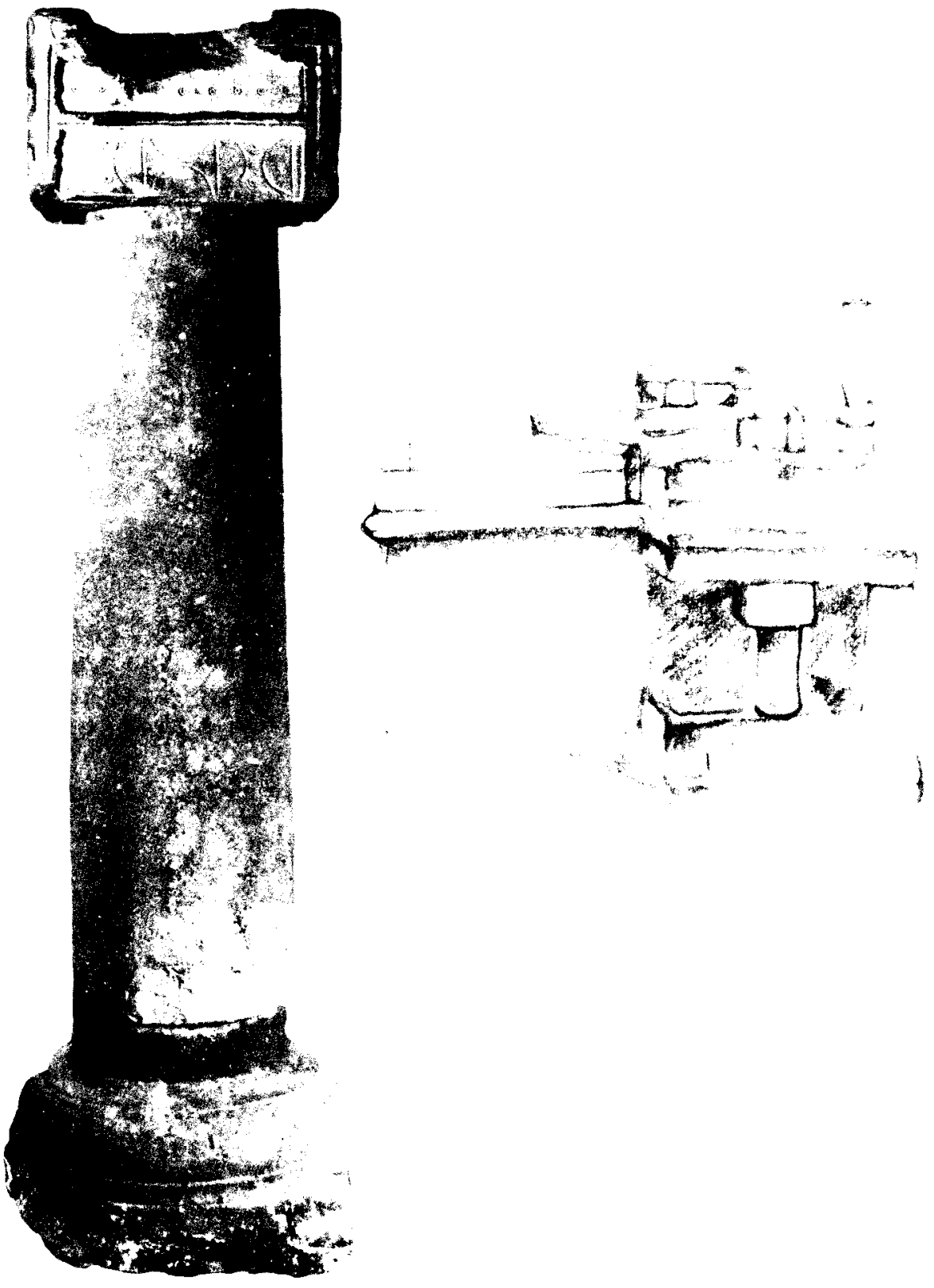

Lam. 1. Cortijo del Ahorcado. La columna tal y como se exhibe en el Museo Arqueológico Nacional (Foto MAN); y dibujo de una maqueta de terracota procedente de Archanes (Tera), tomado de ilustración de L. Morgan. 

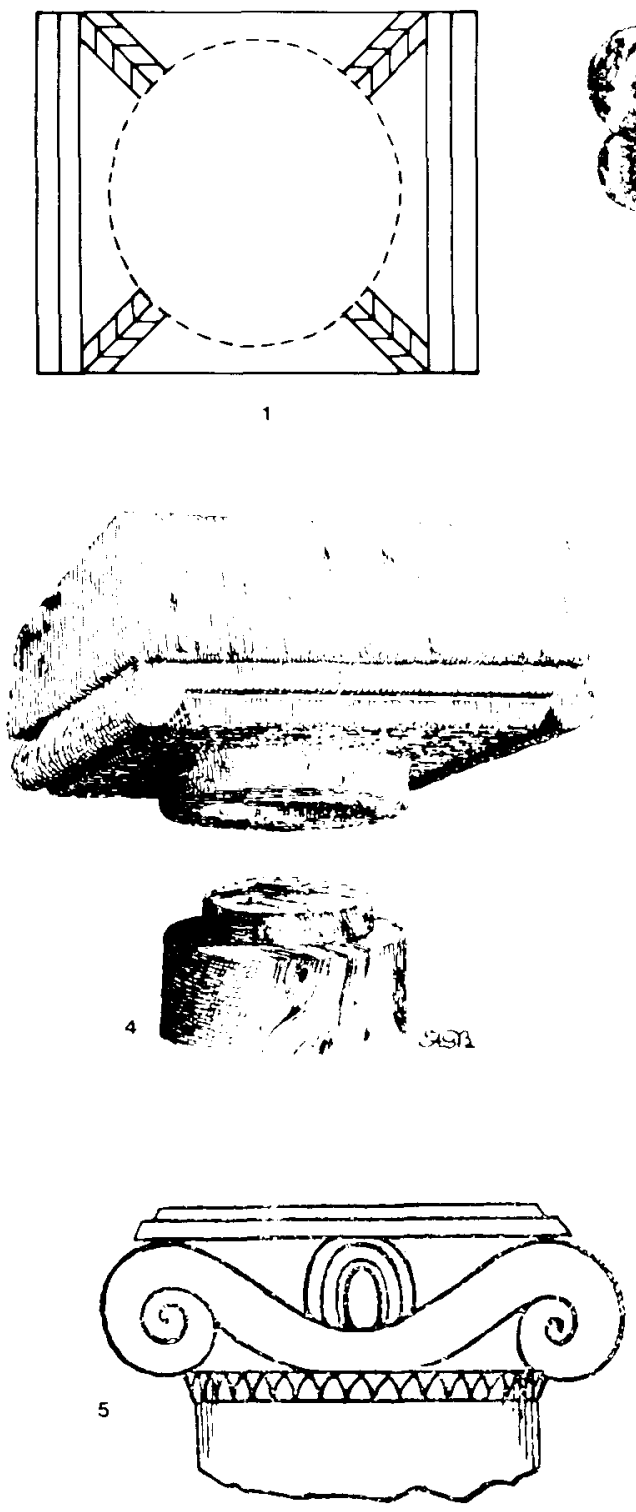
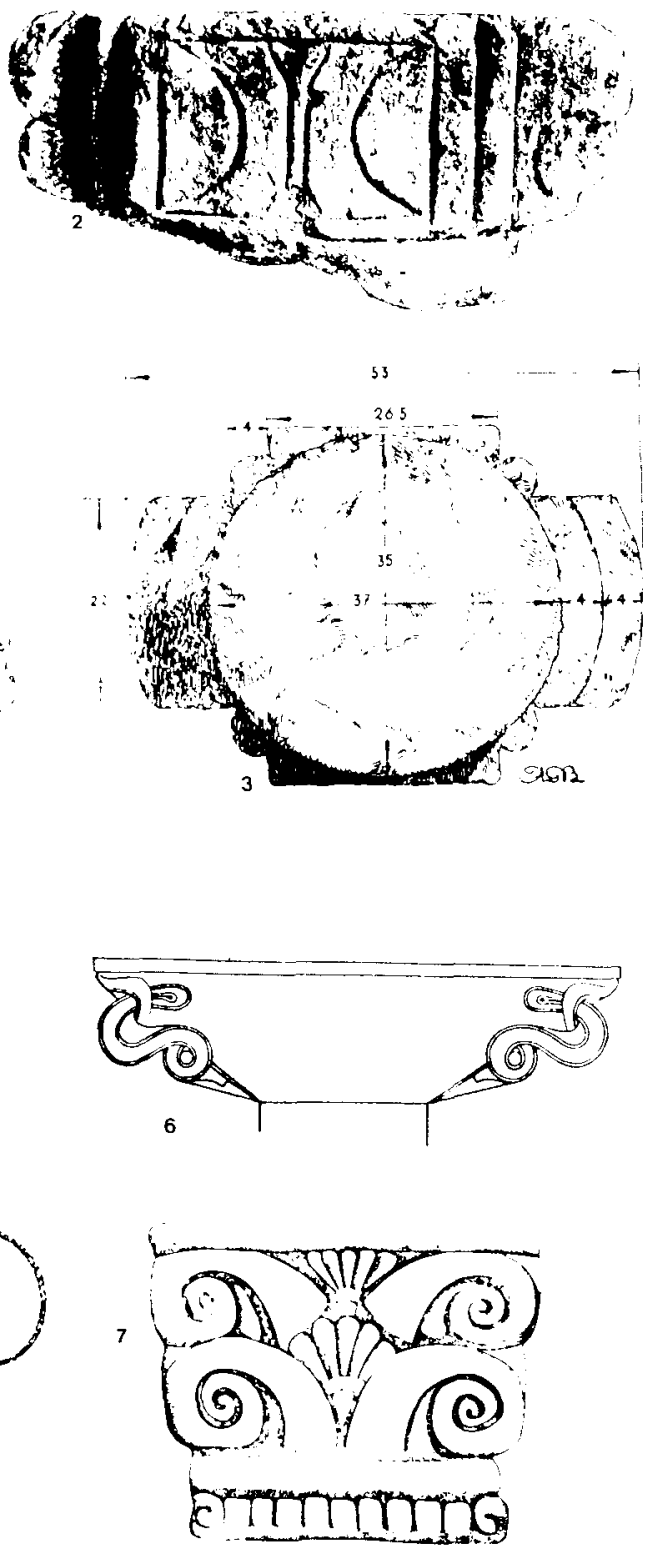

Fig. 1. 1, Esquema de la cara inferior del capitel núm. 1 del Cortijo del Ahorcado. 2 y 3, Capitel núm. 2 del Cortijo del Ahorcado según García y Bellido. 4. Capitel núm. 3 del Cortijo del Ahorcado, según Garcia y Bellido. 5, Capitel del Cerro de los Santos, según Cabré. 6, Zapata de Galera, según Cabré. 7. Capitel de Chiusi, según Ciasca. 
Aporta como novedad tres dibujos: 1) la columna completa según la fotografía de Mélida; 2) la perspectiva "vista desde el collarino" de lo que puede ser otro capitel o "tal vez una zapata" (fig. 1: 3); 3) la ilustración de cómo podría acoplarse a un fuste cilíndrico, el tercero de los capiteles (fig. 1: 4).

Datos y dibujos vuelven a publicarse, prácticamente en los mismos términos, en el año 1953. Este autor insiste en la importancia de las ruinas romanas que "mostraban ser las de unas termas, en el centro de las cuales se reconocía claramente las trazas de un patio rectangular con peristilo y una piscina en medio, revestida de cemento. Las columnas eran diez, de la que tan sólo una conservaba el fuste liso y cilíndrico y ligeramente labrado. De las demás sólo se veían capiteles y basas. El carácter bárbaro y primitivo de algunas de estas piezas acredita el lógico supuesto que en el peristilo se aprovecharon restos de algún edificio indígena, a los cuales, y para completarlos, se les añadieron piezas hechas ya al modo romano" (A. Garcia y Bellido, capítulo de Arte Ibérico, t. I, vol. 3, págs. 435 y ss. y fig. 300, 303 y 305 de la Historia de España dirigida por Menéndez Pidal). Estas publicaciones son la fuente de todas las citas posteriores y únicamente cabe mencionar un expresivo párrafo de la obra Arte ibérico en España, publicación póstuma de A. García y Bellido, cuando al comentar los ecos de Grecia en la ornamentación arquitectónica, a propósito de los restos del Cortijo del Ahorcado dice: «... pero nada de éso muestra ya la columna de Baeza cuyo liso fuste aunque ligeramente disminuido de diámetro en su ascenso, como los clásicos, se corona con un capitel cúbico tan anticlásico, que no puede decirse de él otra cosa sino que es tan ajeno a Grecia como pueda serlo una pirámide Maya. No hay nada en él que sea explicable por las formas ornamentales helenas...” (1980, pág. 26, edición ampliada por A. Blanco).

\section{LA COLUMNA (lám. l)}

Siguiendo las referencias de las publicaciones citadas y nuestras personales apreciaciones la descripción es la siguiente:

Tal y como se exhibe en el Museo, la columna tiene por basa un plinto cuadrado y liso sobre el que se asienta el toro o bocel. Formando cuerpo con esta pieza aparece el arranque de un fuste (altura total del 
conjunto, $39,5 \mathrm{~cm}$ ); sobre este elemento se ajusta y superpone el fuste liso y monolítico de $1,36 \mathrm{~cm}$. de altura, cuyo diámetro $(38 \mathrm{~cm}$. máx.) disminuye progresivamente hasta quedar embutido en la base del elemento denominado capitel.

Como ya observó Mélida y dibujó García y Bellido la basa no es la original, mientras el fuste, a juzgar por el acoplamiento, parece formar un todo orgánico con el cuerpo superior, teoría que presupone el aprovechamiento de elementos arquitectónicos bastante completos y su adaptación al edificio romano.

El llamado capitel es en realidad una caja maciza en forma de prisma rectangular al que conviene más el nombre de capitel de zapata ${ }^{2}$, propio de construcciones lignarias antiguas o de las actuales de hormigón, que la denominación de capitel en sentido estricto. Tiene una altura máx. de $32 \mathrm{~cm}$. y las caras laterales, iguales dos a dos, miden respectivamente $50 \mathrm{~cm}$. (caras a y b) y $42 \mathrm{~cm}$. de anchura (caras c y d). Es decir, tanto la base como la cima forman sendos rectángulos de $42 \times 50$ centímetros.

La base o cara inferior tiene su centro vaciado en forma de seno (ejes máx. $33 \times 36 \mathrm{~cm}$.) para facilitar el acoplamiento del fuste. Los lados menores están enmarcados por molduras en junquillo y las diagonales están indicadas mediante una especie de espiguilla incisa entre líneas paralelas $(4 \mathrm{~cm}$. de anchura y 12 de longitud) que convergen y se interrumpen en el hueco, tal y como se aprecia en el dibujo adjunto (fig. 1: 1).

La cara superior, fragmentada parcialmente, ha sido modificada por un rebaje intencionado cuyo detalle no apreciamos con nitidez pero, parece obvio, que tendría la finalidad de recibir otro elemento.

La ornamentación de las caras laterales enmarcadas por molduras es muy similar y afecta a los cuatro frentes; no obstante, se singularizan por la combinación de los motivos (perfectamente geométricos a regla y compás) ejecutados por incisión. El juego de listeles y el tratamiento de la superficie, vaciada o no, sugieren cierta sensación de relieve, especialmente en las líneas del contorno y en los junquillos divisorios de los

2 D. S. RobertSON, 1981 , págs. 77 y 78 al referirse a construcciones lignarias define el capitel de zapata en los siguientes términos: "un bloque rectangular (no cuadrado) de madera colocado entre la parte superior de un pie derecho y las vigas". Si estos capiteles del Cortijo, según sospechamos, tuvieron función arquitectónica, sus caracteristicas se ajustan bien a esta definición y aunque la materia prima sea la piedra creemos que el apelativo de zapata matiza las diferencias respecto a los capiteles más afines a los de tipo clásico. 
tres registros horizontales comunes a todas las caras, ya sea a nivel superficial (al que se ha llamado "banda") o en plano más bajo (vaciado rectangular a bisel denominado "caja»). Así pues, se añade como elemento ornamental el efecto de profundidad aunque la diferencia apenas rebasa los dos centímetros.

Cara a (lám. II, 1). Limitan los flancos dos líneas paralelas, a modo de columnillas abultadas, prolongadas en los extremos por sendos apéndices cuadrangulares con dos lados cóncavos (el diseño se asemeja al denominado de "piel de buey» o "doble hacha»). Los apéndices más altos flanquean la banda superior $(6 \mathrm{~cm}$.), muy fragmentada, y en la que se aprecia una hilera horizontal de pequeños círculos discontinuos formados por doble aro y punto central.

La decoración interior de la caja central $(8 \mathrm{~cm}$.) lleva otra fila de nueve de estos círculos dispuestos en el centro ${ }^{3}$. Un doble listel la separa de la caja inferior $(12 \mathrm{~cm}$.) que está decorada con la reiteración del motivo bicóncavo inscrito en un rectángulo y repetido en posición vertical (extremos) y horizontal (en el centro). Dos circulitos dispuestos en el eje de este triple motivo completan la decoración.

Cara b (lám. II, 2). Respecto a la cara a) varía el número de estrías (4 en este caso) que separan la caja inferior $(10,5 \mathrm{~cm}$. de altura) y la disposición de los motivos bicóncavos, que aquí están colocados dos veces en horizontal (extremos) y una en vertical (centro).

Cara c (lám. III, 1). En la banda superior (de $6 \mathrm{~cm}$. de altura como en las otras caras) discurre una hilera de diez circulitos. La variante a destacar es que sólo la banda central $(11,5 \mathrm{~cm}$.) está limitada por las columnitas de extremos bicóncavos (la decoración insiste en los motivos y disposición de la última caja de la cara a). La caja inferior $(7,5 \mathrm{~cm}$.), enmarcada por doble listel y ligeramente abarquillada, ostenta como decoracion 12 y 13 círculos concéntricos dispuestos respectivamente en dos hileras.

Cara d (lám. III, 2). Tiene la superficie dañada pero se comprueba bien la división tripartita y una fuerte separación a modo de ranura, entre las dos bandas inferiores. Repite el esquema de la cara $c$ variando el

${ }^{3}$ En el marco superior de la caja central la fotografia insinua el inicio de una tenue línea festoneada que no se aprecia visualmente. Es imposible, dada la altura y las luces, discernir si es intencionada o fruto del azar. El aspecto es muy semejante a la decoración que aparece al borde de la tapa de una urna funeraria ilustrada por Cabré (1920) en lám. XIII. 

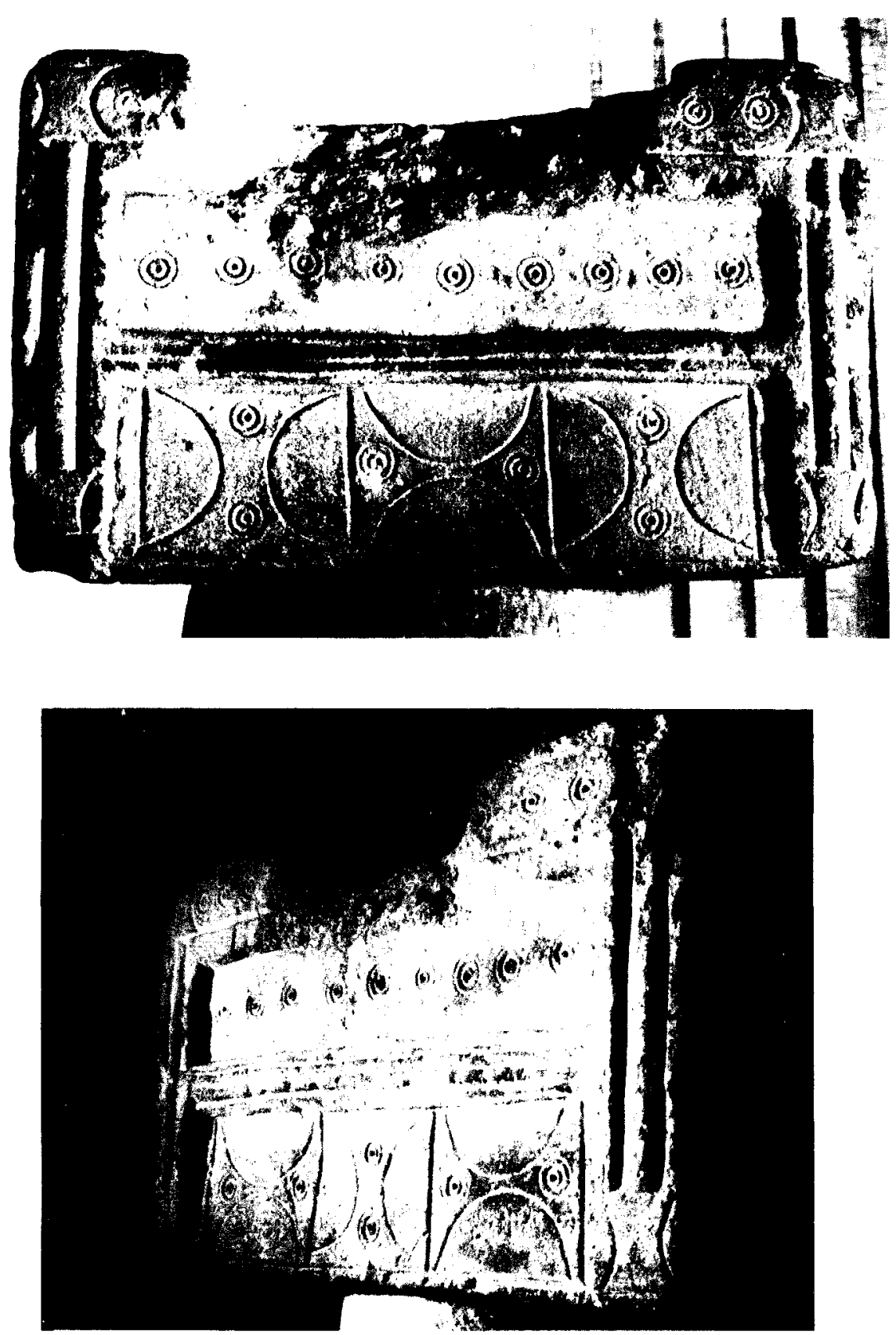

Lám. II. Cortijo del Ahorcado: 1, Cara a del capitel número 1. 2, Cara b del capitel número 1. Fot. MAN. 
El Cortijo del Ahorcado (Baeza, Jaén): estudio de los restos arquitectónicos
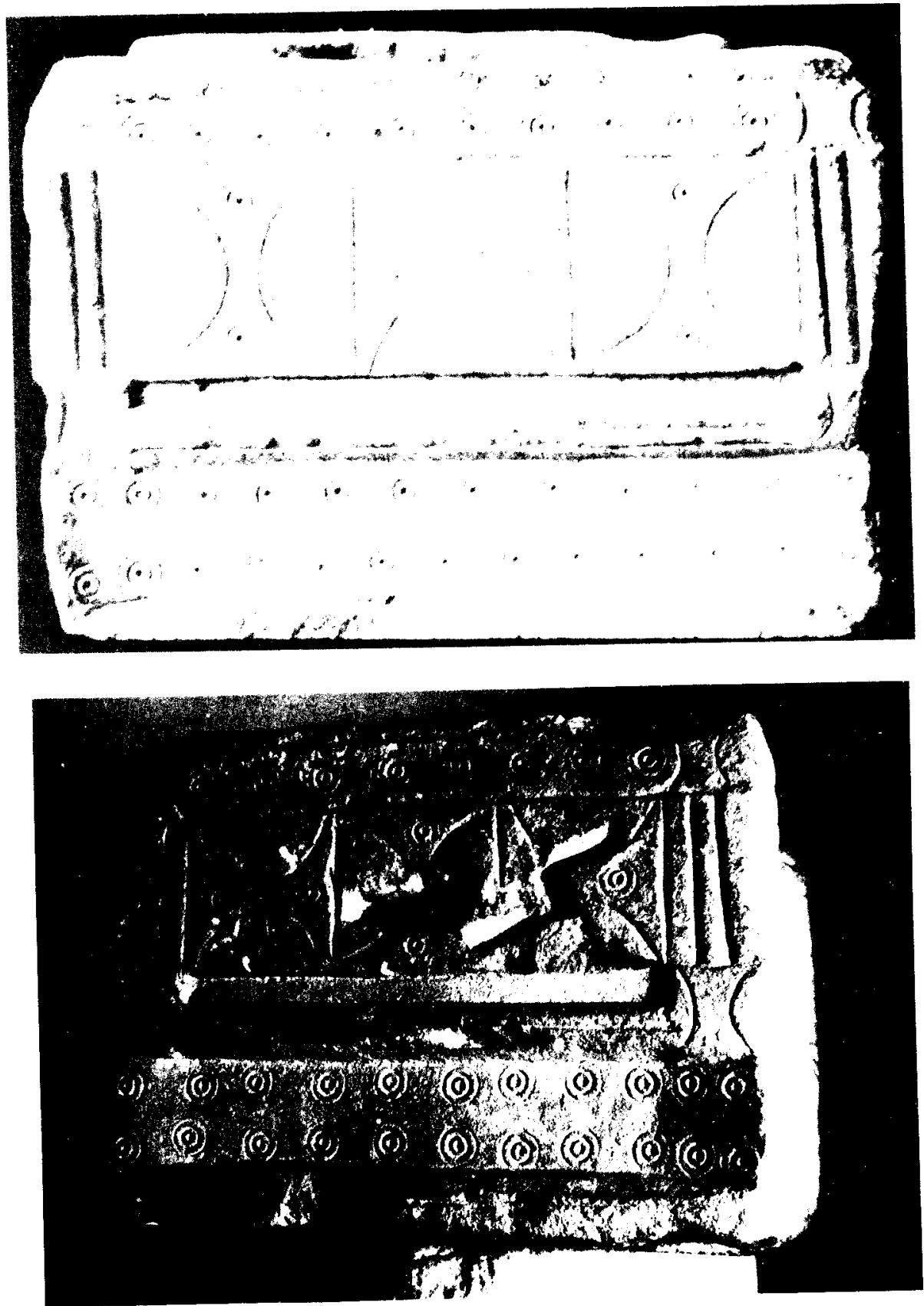

Lám. III. Cortijo del Ahorcado: 1, Cara c del capitel número 1, según Garcia y Bellido. 2, Cara d del capitel número 1. Fot. MAN. 
número de círculos: 8 en la banda superior y dos hileras de 11 circulitos en la inferior (también alabeada y de unos $7 \mathrm{~cm}$. de alto). La banda central $(10 \mathrm{~cm}$.) repite la decoración de los motivos bicóncavos dispuestos como en la caja inferior de la cara $b$.

\section{ANÁLISIS}

\section{A. Forma}

Columnas rematadas en un tipo de "capitel de zapata» muy próximo al que estudiamos debieron utilizarse con cierta frecuencia desde el Minóico Medio. No se conocen ejemplares auténticos sino versiones que atestiguan esta función de sostén empleando, quizá, elementos de madera: en el llamado "Vaso de los Boxeadores» de Hagia Triada, Creta (Handbuch der Architektur, Band I cit. en D. S. Robertson, 1981, pág. 43, fig. 7) se reproduce este modelo de columna muy semejante a la del Cortijo del Ahorcado (fig. 2: 1). El fuste liso y sin basa disminuye de grosor de abajo a arriba y está coronado por un prisma cuadrangular decorado con círculos en relieve, morfológica y técnicamente similar al español. Carece igualmente de equino y remata en un estrecho "cimacio" (quizá representación de la viga sustentada) que actúa de transición a la techumbre. Su función real está constatada en figuraciones minóicas de la isla de Thera y en las maquetas de arcilla localizadas en Archanes (L. Morgan, 1988, L. III c y passim), uno de cuyos ejemplos se ha reproducido para su comparación en lám. I: A. Otro documento a recordar es una terracota de Cnossos (fig. 2: 2) que muestra una columna con un "Capitel» semejante sobre el que se representaron las cabezas de los troncos de madera (A. Beltrán, 1949, fig. 162, 11, III). Troncos o vigas que se repiten, incorporados ya al gran ábaco prismático (en esta ocasión con un equino convexo bien diferenciado), en la famosa columna de la Puerta de los Leones de Micenas (fig. 2: 3) (B. Wesenberg, 1971, lám. 9-11).

Todo ello apoya la hipótesis, argumentada por diversos investigadores, de la existencia de una arquitectura lígnea cuyos elementos, a medida que se trasladaban a la piedra, fueron trasformándose hasta crear el orden dórico. Así se explica que los capiteles arcáicos, con equino y ábaco bien diferenciado, muestren este último elemento a manera de una caja maciza, con un considerable desarrollo: capiteles del Tesoro de 

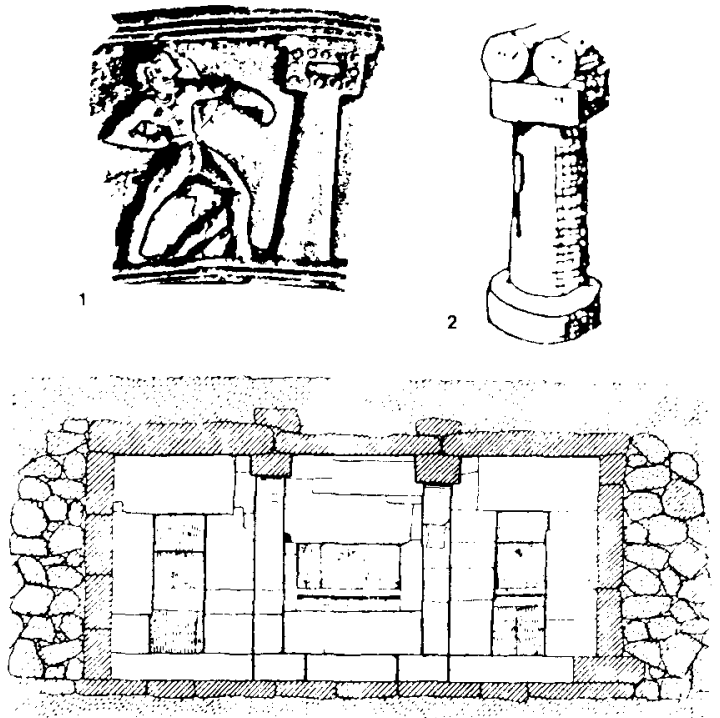

4
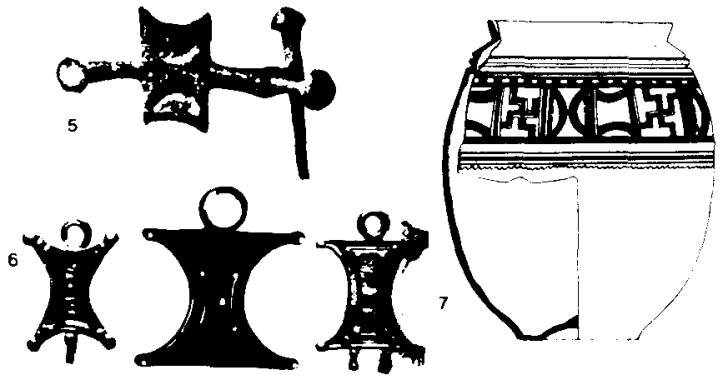
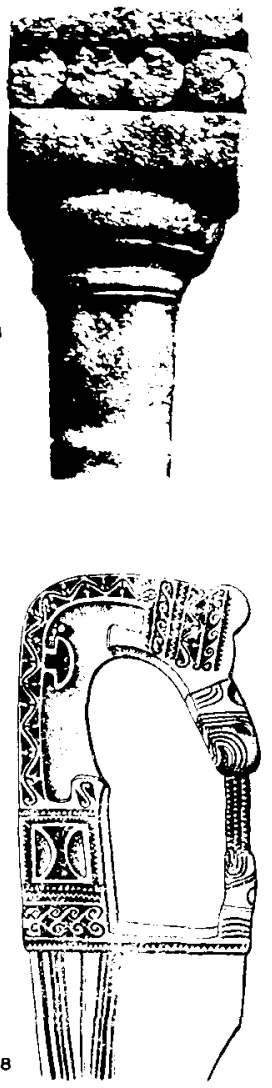

10

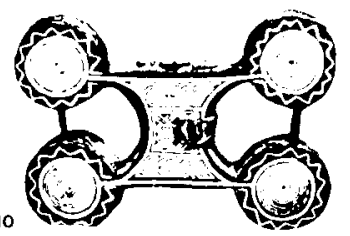

Fig. 2. 1, Detalle del vaso de "Los Boxeadores", según Robertson. 2, Terracota minóica, según Beltrán. 3, Detalle de la columna de la "Puerta de los leones", según Wesenberg. 4, Detalle del alzado de la Cámara de Toya, según Cabré. 5, Fibula del Instituto Valencia de Don Juan, según Almagro. 6. Colgantes del Instituto Valencia de Don Juan. 7, Vasija de Numancia, según Romero. 8, Detalle de la falcata de Almedinilla, según Cabré. 9, Detalle del broche de La Osera, según Cabré. 10, Detalle de la contera del puñal de tipo Miraveche, según Cabré. 
Atreo, del templo de Atenas Pronaia en Delfos - siglo vil-, e incluso los conocidos en los más primitivos templos de Italia Central (D. S. Robertson, 1981, pág. 81). La voluminosa pieza prismática es la que, enlazando teóricamente con los ejemplos minóicos, más que se aproxima en forma y función a este capitel núm. 1 del Cortijo del Ahorcado.

Por otra parte, la morfología de estos ábacos desarrollados, adopten o no formas cúbicas o genéricamente de prisma, se atestigua también en la arquitectura egipcia, en las piezas intermedias entre la columna y el entablamento, que alcanzarán el máximo exponente de su belleza a partir del Imperio Medio, en los denominados capiteles hatóricos o de sistro.

A tenor de estos antecedentes es razonable pensar que el uso de estas "cajas macizas" responde a una solución simple, dentro de la arquitectura adintelada, para favorecer la carga de las vigas y el tránsito entre los elementos sustentados y los verticales que actúan de sostén. La aparición del capitel clásico, consecuencia de la reducción de la zapata prismática —el ábaco- en favor de la pieza inferior que se acopla al fuste - el equino del orden dórico-, así como las diversas modalidades de los capiteles egipcios son una evolución lógica y progresiva que, junto con el desarrollo del fuste, favorecen la esbeltez de los edificios y la distancia en el intercolumnio.

Otro argumento en pro de unos antecedentes semejantes y de una evolución polimorfa se evidencia en la singularidad del llamado capitel protoeólico, pues tal y como indica Y. Shiloh (1979, pág. 16, fig. 9) al teorizar sobre las etapas de su construcción, en la estructura del bloquematriz puede reconcerse, igualmente, el elemento prismático, ya que las volutas y la decoración en relieve no son sino el resultado de ornamentar el mencionado bloque pétreo, aligerando su masa. Es decir, tanto en el orden dórico como en el jónico, el capitel evoluciona a partir de las modificaciones o trasformaciones que sufre la primitiva pieza transicional, común a una arquitectura simple, presente en distintas áreas culturales.

Incluso en aras sacrificales o "mesas de ofrenda", como las representadas en los relieves hititas de Alaca Hüyuk (K. Bittel, 1976, fig. 214) es posible intuir un remedo de los fustes verticales coronados con cajas prismáticas. En cualquier caso, siguiendo con las columnas arquitectónicas, la forma prismática de los capiteles se rastrea también en el remate de las columnas o pilastras etruscas, contaminadas por el influjo y las innovaciones del capitel eólico, tal y como se comprueba en el paradigmático capitel de Chiusi (A. Ciasca, 1962, lám. X, 1).

Una prueba más de la funcionalidad y conservadurismo de esta sencilla solución de apoyo proviene de la arquitectura romana. No faltan 
ejemplos de termas donde las columnas de los "hipocausta" rematan en estas almohadillas prismáticas (bien conservadas p. e. en las de Campo Valdés de Gijón), utilizadas también en obras de ingeniería.

En el mundo ibérico la documentación conservada apenas permite un somero rastreo sobre los orígenes. Nada impide aceptar la existencia de una arquitectura lígnea de mayor envergadura que la propia de cabañas en ramaje, ya que no faltan ejemplos de poblados de la Primera Edad del Hierro con postes de sustentación revestidos de arcilla y con decoración pintada o en relieve. Aun cuando ignoremos cómo era en realidad la solución del alzado es lógico suponer que estas construcciones fueran el modelo más directo para el trasunto en piedra de los postes verticales. Salvo contados ejemplos de edificios sacros no bien documentados o en estudio, sólo los yacimientos de naturaleza funeraria han proporcionado testimonios de una arquitectura en piedra más sofisticada, que se aparta de las construcciones defensivas propiamente dichas o de los basamentos de las casas. La techumbre de la cámara adintelada de la tumba 75 de la necrópolis granadina de Galera tenía como sostén central una pilastra cuadrangular coronada por una "zapata" con funciones de capitel (fig. 1: 6) (J. Cabré, 1920, pág. 56). En los remates ornamentales se reconoce la deuda de los influjos externos y en la estructura troncopiramidal es fácil detectar, al igual que en el capitel protoeólico, su factura a partir de un bloque prismático. Precisamente el uso de este tipo de bloques para descargar las vigas trasversales, esta vez sin ninguna modificación ornamental, está bien documentado en la famosa cámara funeraria de la necrópolis de Toya (Peal del Becerro, Jaén) (fig. 2: 4), (J. Cabré, 1925). Estos dos ejemplos funerarios, cada uno a su manera, prueban la adopción de soluciones parecidas y, en consecuencia, es presumible que capiteles como los del Cortijo del Ahorcado gozaran de cierto favor en la arquitectura ibérica debido a una tradición autóctona y no al eco de corrientes externas.

En apoyo de esta afirmación recordamos la reiteración de la forma de piedra de prisma cuadranaular en los conocidos capiteles del Llano de la Consolación (Montealegre del Castillo, Albacete) (A. Garcia y Bellido, 1953, pág. 410) y de Martos (Jaén) (C. Fernández Chicarro y A. Recio, 1959, pág. 155). Reminiscencia de esta forma puede rastrearse incluso en capiteles más recientes como el de Cástulo (J.M. Blázquez et alii, 1984, pág. 276) o en la pequeña ara votiva en forma de capitel, localizada en el Santuario de Castellar de Santisteban, también en Jaén (R. Lantier, 1917, pág. 21-23). 


\section{B. Decoración}

Aunque este capitel del Cortijo del Ahorcado es muy singular en la decoración, el modo de dividir la superficie y el juego de planos con efectos de luz y sombra son recursos bien conocidos en los relieves ibéricos, destacando por la similitud morfológica las cajas funerarias de piedra. Valgan como ejemplo las cistas cinerarias procedentes de la necrópolis de Galera.

Ciñéndonos a los motivos ornamentales es ocioso insistir en la decoración de dobles círculos con punto central, presentes en distintos ambientes culturales, en todo tipo de materiales (metal, marfil, hueso, cerámica...), y bien representados en numerosos objetos de la cultura ibérica.

Mayor consideración merece el motivo bicóncavo ya sea con las escotaduras libres o encerrado en un rectángulo. La silueta abierta puede considerarse un trasunto tanto de la "doble hacha" (vide dibujo similar en fig. 106 de L. Morgan) como de la denominada forma en "piel de buey». Esta última hipótesis está argumentada en los singulares colgantes del Instituto Valencia de Don Juan (fig. 2: 6) procedentes del NO. (F. López Cuevillas, 1951 y A. Blanco, 1957, lám. VI y VII) idénticos a los localizados en Palencia. El origen continental de estas piezas se evidencia porque son una réplica casi exacta de los llamados «amuletos en reloj de arena", a los que se atribuye un carácter lunar (G. Kossack, 1954, lám. 16, núm. 21 y 22) ${ }^{4}$.

El esquema concreto de "piel de buey" se paraleliza también con la forma de los lingotes creto-chipriotas, difundidos por el Mediterráneo. El famoso pectoral del tesoro del Carambolo repite esta silueta, que encontramos a su vez en el pavimento de guijarros que circundaba el monumento de Pozo Moro (Albacete) (M. Almagro Gorbea, 1978, pág. 232). La forma se documenta asimismo en joyas ibéricas como la ostentada por una de las esculturas femeninas del Cerro de los Santos (AB-336 según estudio de E. Ruano, 1987, t. I., pág. 154 notas 25 y 26).

En cualquier caso gozó de más favor la variante con dos lados rectos. Quizá los más antiguos ejemplos peninsulares están representados en las cerámicas de la Meseta justamente en la fase de apogeo del

\footnotetext{
${ }^{4}$ Medias lunas contrapuestas se reiteran como elementos simbólicos en el mundo fenicio-púnico, especialmente en las estelas, si bien el mismo motivo se constata en cerámicas protovilanovianas.
} 
horizonte de Cogotas I (primeros siglos del primer milenio a.C.). La disposición encadenada o matopada recuerda mucho la hilera de nuestro capitel y la semejanza es todavia mayor en una de las vasijas procedente de los Areneros del Manzanares: lleva también circulos dobles en el eje central de cada motivo (M. D. Fernández-Posse, 1984, pág. 484, fig. 2, $14,17,20$ y 21). Intencionadamente no se insiste en los paralelos extrapensulares (E. Echevarría, 1988) pero debe recordarse que es a partir de la primera edad del hierro cuando los ejemplos se multiplican (caso de las citadas joyas castreñas) coincidiendo con la persistencia en los enterramientos "tartésicos" de los extraños objetos denominados "brazales de arquero" (M. R. Lucas, 1981, pág. 262, nota 29) y la presencia de joyas tan singulares como las del Cortijo de Ebora (San Lúcar de Barrameda, Cádiz) donde la ecuación medias lunas-rectángulo bicóncavo es incuestionable (J. Carriazo, 1970).

Prueba de la intencionalidad de tales diseños es la presencia de estas medias lunas contrapuestas y encerradas en caja rectangular en el puente de una excepcional fíbula conservada en el Museo Valencia de Don Juan, de clara filiación europea, datable en el Hierro Antiguo (fig. 2: 5) (M. Almagro, 1952, pág. 229, fig. 203). Por otra parte debe recordarse que las placas de cinturón de uno o más gartios adoptan esta forma escotada ya sea abierta o cerrada. Sobre su simbología y trascendencia se ocupó J. A. Morán en 1975 y 1977. Para mayor abundancia cabe señalar que alguno de estos broches repite en su decoración este motivo (ejemplar recientemente descubierto en una necrópolis de Albacete). El dibujo aparece igualmente en broches de cinturón de placa rectangular (fig. 2: 9) caso del localizado en la sepultura 712 de La Osera (Chamartín de la Sierra, Ávila) (J. Cabré, 1937, lám. XI).

El esquema adoptado por las conteras abiertas o cerradas (fig. 2: 10) y la reiteración del motivo en los nielados de los puñales de tipo Miraveche-Monte Bernorio (B. Griñó, 1983) constatan suficientemente la predilección de la Meseta por este motivo, repetido en numerosas variantes en la pintura vascular de Numancia (fig. 2: 7), (J. Romero, 1974 y 1976) al igual que en las del círculo ibérico de Azaila (J. Cabré, 1944).

Para concluir basta recordar, dentro del área ibérica, la decoración de la falcata de Almedinilla (fig. 2: 8), (M. E. Cabré, 1934, lám. II y II; G. Nieto y J. Escalera, 1970, fig. 3) y, lo que es más elocuente, la presencia del mismo motivo en otros fragmentos arquitectónicos: el capitel núm. 2 del Cortijo del Ahorcado (fig. 1:2) y las piezas inventariadas con los núms. 181 y 183 en el Museo de Cástulo (R. Lucas y E. Ruano, 1989). 


\section{CAPITEL CON PSEUDOVOLUTAS (fig. 1: 2 y 3)}

Según descripción de Mélida y dibujos de García Bellido, sabemos que las dimensiones se aproximan a las del capitel anterior. Está formado por un cuerpo prismático de $22 \mathrm{~cm}$. de altura y tiene las caras rectangulares $(37 \times 35 \mathrm{~cm}$.) con esquinas en escalón. La base se prolonga en un saliente cilíndrico corto (unos $8 \mathrm{~cm}$.) que, a juzgar por las apreciaciones de García y Bellido, es macizo. En conjunto, la pieza alcanza unos ejes máximos de $53 \times 35 \mathrm{~cm}$. y la altura total (incluida la parte inferior) se aproxima a los $32 \mathrm{~cm}$. Estas medidas incluyen dos resaltes en media caña (“pseudovolutas") yuxtapuestos verticalmente en cada flanco del prisma y de unos $4 \mathrm{~cm}$. de vuelo. Están delimitados por una línea incisa en forma de $S$ y la visión lateral debe acusar esta curvatura doble, decorada con alguna otra incisión.

Solamente conocemos la decoración fuertemente incisa y desmanada de uno de los frentes: un motivo bicóncavo, encajado en un rectángulo, que alberga en el interior, justamente en el centro, una especie de columnilla con extremos acampanados (el dibujo, a diferencia de las columnillas del capitel 1, recuerda la representación esquemática de un "pebetero"). Presumiblemente la cara opuesta debe estar decorada.

\section{ANÁLISIS}

\section{A. Forma}

La morfología de este capitel, a pesar de las diferencias admite comparación con el anterior dado que su estructura se contorma a partir de un bloque prismático. La diferencia viene impuesta, por una parte, por la presencia del cuerpo cilíndrico labrado en el mismo bloque, casuista que se repite en el capitel número 3 y puede explicarse como un recurso dirigido a solucionar el encaje con el fuste. Por otra, además de las esquinas escalonadas, hay que valorar la presencia de las "pseudovolutas" laterales que Garcia y Bellido comparó con la zapata de la Galera (fig. 1:6). Este remate en doble curvatura se conoce en otros fragmentos arquitectónicos (p. e. "la zapata» de Elche). No está resuelto el antece- 
dente inmediato de esta versión ibérica. Entre los llamados capiteles eólicos, considerados como fuente directa del orden jónico, no faltan ejemplos que llevan debajo de las enormes volutas "SS" opuestas o dos pequeñas hojas (caso del capitel M2 de Megido cuyo reverso marca un escalón: Y. Shiloh, 1979, lám. III). La imitación del perfil de esta doble curvatura pudo llevar al tratamiento homogéneo de ambos elementos enlazados entre si con el adorno en $S^{5}$ pero también cabe pensar que estemos ante una representación intencionada de volutas paralelas, tal como se plasmó en los anillos de la Aliseda que muestran tanto la doble voluta yuxtapuesta como la sucesión en serie (J. M. Blázquez, 1975, pág. 133-136), al modo de los capiteles etruscos (fig. 1: 7), (A. Ciasca, 1962). En cualquier caso, si se trata de imitar auténticas volutas, se han interpretado muy esquemáticamente al igual que en la "ménsula" de Martos (Jaén), (C. Fernández Chicarro y A. Recio, 1959, pág. 152).

\section{B. Decoración}

Basta con remarcar la reiteración del motivo bicóncavo enmarcado en la cara frontal. La técnica es más rudimentaria que en el capitel núm. 1 y desde luego los arcos no están trazados a compás (más fuerte la incisión, casi biselada en las medias lunas). El hecho de llevar en el centro el extraño dibujo en forma de columnilla o pebetero, hace suponer, por analogía ideológica con el capitel 1 , que se trate efectivamente de una columnilla con función de ara, representación que en ambiente mediterráneo y en diferentes versiones, es frecuente tanto en objetos muebles como en estelas, ya sea en el centro o flanqueando esquinas y cuyo sentido genérico, aunque sea polivalente, se relaciona con la evocación del llamado "árbol de la vida» o con la presencia de la divinidad (hierofanía).

\section{CAPITEL DE VOLUTAS (fig. 1: 4)}

El dibujo de García y Bellido ilustra la existencia de un cuerpo prismático (una especie de gigantesco ábaco) en el que se ha marcado,

${ }^{5}$ En la diadema del tesoro de la Aliseda se documenta ya la evolución esquemática de la palmeta y las SS afrontadas. 
mediante una ranura acanalada, una estrecha faja rectangular rematada en rígidas volutas (los respectivos rollos cilíndricos decorarian los laterales). En la parte inferior un rebaje a bisel diferencia el teórico equino, que en este caso no es sino una mínima franja de cuyo centro arranca un elemento cilíndrico, vaciado en el interior, que, según la teoría de García y Bellido, actuaría de collarino y albergaría en el interior el fuste. No tenemos referencias de las medidas ni de otro tipo de ornamentación.

\section{ANÁLISIS}

Persiste el cuerpo prismático pero, sin ajustarse a cualquier norma canónica, se añaden las "bárbaras" volutas a manera del estilo jónico. Una abismal diferencia técnica y artística separa esta imitación de la elegancia conseguida en el capitel procedente del Cerro de los Santos (fig. 1: 5) en donde se aprecia ya la existencia de collarino siguiendo la línea adoptada por los capiteles de tradición púnica, según el estudio de Lezine (1961, fig. 41, pág. 79). Por ello, aunque las volutas remitan al orden jónico, no se debe descartar un probable influjo púnico para esta modalidad de capitel localizado en el Cortijo del Ahorcado...

Sea como fuere, este capitel no es sino un burdo remedo del capitel clásico porque tanto las proporciones de los distintos elementos como el trazado de las volutas denotan que se conocen modelos de este género pero no se ha superado todavía la tradición indígena de los cuerpos prismáticos ni se domina la gracia y el modelado de las curvaturas.

Se puede concluir el análisis de los tres capiteles del Cortijo del Ahorcado, haciendo notar la semejanza morfológica de los cuerpos superiores y la similitud de compartir como matriz de la estructura un bloque prismático de caliza blanda y fácil de trabajar. La labra es, en todas las piezas, muy sencilla, propia de instrumentos rudimentarios como el cincel de boca recta. Una vez desbastada la forma, el alisado por simple frotamiento o mediante otra manipulación bastaria para obtener la curvatura de los adornos o la forma troncocónica del fuste. Listeles e incisión (en el caso del capitel núm. 1 con empleo de compás), geometría de los planos y aspecto general parecen más propios del trabajo de la madera que del oficio de cantero. 


\section{PROCEDENCIA Y FUNCIONALIDAD}

Estas piezas que, como se ha visto, pertenecen a la cultura ibérica, plantean una serie de interrogantes. El primero y no menos importante es el de su procedencia. Hasta la fecha dentro del término de Baeza no se han documentado otros restos arquitectónicos o escultóricos distintos a los recogidos en el Cortijo del Ahorcado. En el mismo municipio se conoce el yacimiento ibérico de La Muralla pero, que sepamos, no ha proporcionado restos comparables. Por otra parte son numerosos los yacimientos documentados en la zona. En el cercano término de lbros se halla el llamado Túmulo de Guadalimar (Hornos del Guadalimar), además de una necrópolis y un recinto (J. L. Carrasco, 1984, pág. 8). En Puente del Obispo, al Sur de Baeza, también se localiza el oppidum ibérico del Cerro del Serón (Cortijo Gil de Olid) (A. Ruiz y J. T. Cruz, 1985, pág. 39). A su vez hay que contar con la proximidad de los hallazgos escultóricos de Lupión y Úbeda la Vieja. Precisamente de esta útlima localidad procede una cabeza femenina (probablemente de una esfinge), un toro (M. Bleche y E. Ruano e. p.) y dos leones con presa humana (T. Chapa, 1980 , t. I, págs. 499 y 501). Aparte hay que considerar el hecho de que los leones ibéricos de la fuente pública de Baeza, según todos los indicios, proceden de Cástulo, distante $30 \mathrm{~km}$.

No debe rechazarse la existencia en el lugar de algún yacimiento ibérico anterior a la construcción romana, cuestión que de momento no podemos abordar por insuficiencia de datos, pero sí, como se comprueba en otros yacimientos, los restos arquitectónicos se asociaban a estructuras pétreas, tengan o no esculturas, no debe descartarse la posibilidad de que en época romana se hubieran transportado éstos $u$ otros restos desde alguna zona no muy lejana hasta los terrenos del actual Cortijo.

Respecto a la "función» ningún investigador ha puesto en duda que las piezas, en origen, coronaran columnas y cumplieran por tanto la función de capitel. Tal y como se ha descrito y se exhibe en el MAN, es posible que el fuste liso formara parte del conjunto 1 y que los extraños remates cilíndricos de los capiteles 2 y 3 documenten versiones de tanteo dirigidas a solucionar el acoplamiento al fuste y el tránsito del prisma al cilindro. Desgraciadamente la información sobre cómo serían las primitivas columnas ibéricas es muy limitada y se basa únicamente en contados ejemplos de iconografía: fragmento cerámico de Santa Catalina del Monte (Verdolay, Murcia) con una escena de culto (M. Jorge Aragoneses, 1969 , p. 200); fragmento arquitectónico procedente de Torreparedones 
(Jaén) en el que se representa una columna rematada en capitel zoomorfo (J. Serrano y J. A. Morena, 1989, con biliografía de los paralelos); "capitel» prismático de Osuna (Sevilla) con columna de volutas en la cara central (A. García y Bellido, 1953, fig. 298). En todos los casos el fuste es troncocónico y en los dos últimos ejemplos estriado y de una sola pieza ya sea con basa o sin ella.

En el conjunto 1 del Cortijo del Ahorcado el fuste es también ligeramente tronconónico y de una sóla pieza. «El canon muy bajo y pesado» fue valorado ya por García y Bellido quien no se pronunció claramente sobre su filiación indígena o romana (1953, p. 435) sin embargo, este módulo nada esbelto y hasta cierto punto "achaparrado" es comparable a los citados ejemplos andaluces. Podría aducirse como antecedente el influjo de corrientes externas, pero, como se ha expuesto, cabe pensar que se trata de un recurso sencillo y racional dirigido a solucionar la dicotomía peso y gravedad, aliviando el empuje central de carga y aplicado indistintamente tanto a construcciones de madera como de piedra. A medida que la moda mediterránea calara en las distintas regiones la adaptación de elementos y las recreaciones debieron multiplicarse.

Los escasos testimonios con representaciones de columnas apoyan la idea de que los elementos decorativos descritos como tales sean auténticas columnas, máxime si se tiene en cuenta el parangón morfológico con la pieza de Osuna y la analogía de la disposición decorativa respecto al capitel número 2 del Cortijo. Si la hipótesis fuera cierta, la realidad teórica implicaría la existencia de basas en simetría con el capitel, ya sea prismáticas (como insinúa el capitel 1) o troncocónicas (como se sugiere en el capitel 2), cuestión que no descarta la posibilidad de aras o estelas imitando columnas a manera de los mencionados ejemplos minóico e hitita y de cuanto se conoce en relación con la simbología de motivos verticales de carácter vegetal y su hipóstasis en "thymiateria» o columnas tan prodigadas en el arte fenicio-púnico. La representación de columnas es tema frecuente en las estelas de ambiente cartaginés y justamente la coraza de Ksour es-Saf (s. III-II, Museo del Bardo) exhibe seis columnillas de fuste estriado y basa como parte de su decoración (I Fenici, 1988, p. 68 y 69).

Por otra parte es lícito plantear la hipótesis de posibles altares votivos, más o menos monumentales, a semejanza de la reconstrucción propuesta por E. Llobregat (1984, p. 302) en relación con el complejo templario de La llieta dels Banyets (Alicante).

Retomando la idea de que las piezas que estudiamos pertenezcan a columnas exentas, sería un dato más a tener en cuenta para la futura 
reconstrucción de algunos de los restos ibéricos citados para parangón y susceptibles de atestiguar nuevos monumentos influidos por las corrientes externas. Precisamente el análisis morfológico de los capiteles núm. 2 y 3 del Cortijo del Ahorcado prueba la transición o la adaptación a nuevos modelos arquitectónicos sin asimilar completamente las innovaciones. El resultado, tanto en cuanto afecta a la columna en sí como al formato de las volutas o a las proporciones, delata la imitación de algo conocido pero que por condicionamientos ideológicos o más probablemente por falta de maestría no se sabe hacer.

En cualquier caso el problema no está sólo en explicar la extraña forma adoptada en los capiteles - prisma cuadrangular- y la hipótesis sobre la columna, sino en cuestionar la función y la singularidad de cada pieza.

La disimilitud entre los tres capiteles y el hecho de que nos enfrentemos a estructuras que tienen una tradición común interpretada localmente por distintos artesanos, confirma que estos elementos arquitectónicos no formaron parte de la misma construcción. Consecuente su función debe individualizarse, teniendo en cuenta: 1) la visión frontal de las caras laterales; 2) la posibilidad de que fueran aislados; 3) la altura alcanzada de acuerdo a las medidas atestiguadas en la columna completa.

$\mathrm{Si}$, por otra parte, se considera que estos restos ibéricos tal vez fiseron trasladados desde un mismo lugar y que cuando se reutilizaron debian estar en buen estado, nada se opone a suponer, a tenor de lo que hoy se sabe sobre arquitectura funeraria, que el sitio primitivo estuviera dedicado a necrópolis y las toscas columnas, a semejanza de la pilastra de Galera, soportaran el techo de cámaras funerarias destruidas en época romana. Si esta hipótesis es correcta, la necrópolis tumular de Ibros, es, por ahora, la que más encajaría dentro del supuesto, aunque no excluya una utilización externa a manera de columnas sagradas o de altares votivos.

\section{CRONOLOGIA}

Los argumentos cronológicos no son otros que los inferidos por razonamientos estilísticos y por la valoración subjetiva del arcaismo: un momento en donde el peso autóctono es todavía fuerte y la arquitectura 
local no ha asimilado completamente los cambios aportados por vía mediterránea. Influjos ciprofenicios se rastrean en el capitel núm. 2, posiblemente más contaminados por la corriente púnica que por la jonia, al menos éso se desprende del análisis del capitel núm. 3 y del gusto por el tema de las columnillas.

Ello hace suponer, no sin reservas, que las columnas coronadas por estos singulares capiteles fueron erigidas con anterioridad al siglo iv antes de nuestra era $o$, al menos, en la etapa que precede al dominio bárcida. 


\section{BIBLIOGRAFÍA}

ALmaGro BASCH, M. 1952: «La invasión céltica en España» en $H^{a}{ }^{a}$ de España dirigida por R. Menéndez Pidal, t. I, vol. II.

Almagro Gorbea, M. 1978: "Los relieves mitológicos de Pozo Moro" $T P$, núm. 35, págs. 251-270.

-: 1983: "Arquitectura y sociedad en la cultura ibérica», Coll. Int. Architecture et Societé de l'Archaisme Grecque a la fin de la Republique Romaine (1980), Roma, pág. 387 y ss.

Beltran, A. 1949: Arqueología Clásica, Cartagena.

BITTEL, K. 1976: Los hititas, Madrid.

BLANCO, A. 1957: "Origenes y relaciones de la Cultura Castreña», Cuadernos de Est. Gallegos, T. XII, núm. 36, págs. 5-28.

BLAZQUEZ, J. M.1975: Tartessos y los origenes de la colonización fenicia en Occidente, Univ. de Salamanca.

- 1984: et alii: “Castulo IV", E.A.E., núm. 105.

BLECH, M., y RUANo, E. (en prensa): «Zwei iberischen Skulpturen aus Úbeda la Vieja", Mad. Mit., núm. 30.

CABRÉ, J. 1920: La necrópolis ibérica de Tútugi (Galera, provincia de Granada), Mem. núm. 25, Junta SE y A.

- 1925: Arquitectura Hispánica. El sepulcro de Toya», A.E.A. y A., núm. 1 , pág. 73 y ss.

- 1928:«Decoraciones hispánicas», A.E.A. y A., núm. 11, sep. 14 pág.

- 1937: "Broches de cinturón de bronce damasquinados con oro y plata", A.E.A. y A., núm. 38, págs. 93-126.

- 1944: Cerámica de Azaila, Corpus Vasorum Hispanorum, Madrid.

CABRE, M. E. 1934: "Dos tipos genéricos de falcata hispánica", A.E.A. y A., núm. 10, págs. 207-227. 
Carrasco, J. L. 1982: Panorama arqueológico de la Provincia de Jaén, Pub. Museo de Jaén, núm. 9.

CARRIAZO, J. DE LA M. 1970: «El tesoro y las primeras excavaciones de Ebora», Exc. Arq. Esp., núm. 69, Madrid.

CIASCA, A. 1962: /l capitello detto eolico in Etruria, Univ. de Roma.

ChAPA, T. 1980: La escultura zoomorfa ibérica en piedra, 2 vol. Univ. Complutense. Madrid.

ECHEVARRIA, E. 1988: “Penvivencia y simbolismo del bitriángulo en las marcas de cantero". Actas V Col. Int. de Gliptografía, 1986, Pontevedra.

Fernández Chicarro, C., y Recio, A. 1959: «Objetos procedentes de Martos, Jaén y su término", Bol. Inst. E. G., núm. 20, págs. 121-159.

Fernandez Posse, M. D. 1984: “La Cultura de Cogotas I» en Homenaje a Luis Siret, Madrid, págs. 475-487.

Garcia y Bellido, A. 1945: La arquitectura entre los iberos. Univ. de Madrid.

- 1953: "Arte ibérico. Arquitectura» en Historia de España dir. por R. Menéndez Pidal, t. I, vol. 3, págs. 373-441. Madrid.

-, 1980: Arte ibérico en España, edición aumentada por A. Blanco), Madrid.

Jorge Aragoneses, M., 1969: «El vaso de Santa Catalina del Monte», A.E.A., núm. 42, págs. 200-204.

Griño, B., 1983: Los puñales del tipo Monte Bernorio-Miraveche, Mem. de Licenciatura en prensa (Serie int. B.A.R.).

Kossack, G., 1954: Studien zur Symbolgut der Urnenfelder- und Hallstattzeit Mitteleuropas, Röm. G.F., núm. 20, Berlín.

LANTIER, R., 1917: El santuario ibérico de Castellar de Santisteban, Mus. de Ciencias Naturales, Madrid.

Lezine, A., 1962: Architecture punique. Recueil de Univ. de Tunis, Documents Série: Arch.-Hist. vol. 5, París.

LOPEZ CUEVILLAS, F., 1951: Las joyas castreñas, Madrid.

LUCAS, M. R., 1981: "Santuarios y dioses en la Baja Época Ibérica", en Actas Mesa Redonda sobre la Baja Época de la Cultura lbérica (Madrid, 1979), As. E.A.A., págs. 233-293.

LuCAS, M. R., y RUANo, R., 1989: «De Arquitectura Ibérica; Identificación de una fachada monumental en Cástulo (Jaén)". En prensa.

Llobregat, E., 1984: “Un altar de perfumes de tipo oriental en el yacimiento ibérico de La llleta de Banyets (El Campello, Alicante)", Bol. Ar. E. del Oriente, año XXIV, Univ. Autónoma de Madrid.

MeLidA, J. R., 1923: Museo Arqueológico Nacional. Adquisiciones de 1920, “Notas descriptivas", pág. 8 y ss. 
MORÁN, J. A., 1975: «Sobre el carácter votivo y apotropáico de los broches de cinturón en la Edad del Hierro peninsular", XIII C.N.A. (Huelva, 1973), Zaragoza, págs. 603-610.

- 1977: "La exponencia femenina y la signografía ofídica en broches de cinturón del Hierro Hispánico", XIV C.N.A. (Vitoria, 1975), Zaragoza, págs. 611-615.

Morgan, L., 1988: The Miniature Wall Paintings of Thera. A Study in Aegean Culture and lconography., Cambridge Univ. Press.

Nieto, G., y Escalera, A., 1970: “Estudio y tratamiento de una falcata de Almedinilla", Informes y Trabajos del ICROA, núm. 10, págs. 5-13.

RoberTson, D. S., 1981: Arquitectura griega y romana, Madrid (Reimp.)

ROMERO, J., 1974: “Simetría y composiciones en la pintura cerámica de Numancia. Análisis de algunos aspectos", Estudia Archaeologica, núm. 32, Valladolid.

-, 1976: Las cerámicas polícromas de Numancia, Col. Bibl. Soriana.

RUANO, E., 1981, a: "Aproximación a un Catálogo de Escultura Ibérica en las provincias de Sevilla. Cádiz, Granada, Almería y Málaga", Bol. As. E.A.A., núm. 14, pág. 19 y ss. Madrid).

-, 1981, b:«Aproximación a un Catálogo de Escultura lbérica en la Provincia de Córdoba», Bol. As.E.A.A., núm. 13, pág. 25 y ss. Madrid).

-, 1983: "Aproximación a un Catálogo de Escultura lbérica de la Provincia de Jaén". Cuad. de Pre. y Arq., núm. 9-10, Universidad Autónoma de Madrid, págs. 67-107.

-, 1987: La Escultura Humana de piedra en el Mundo Ibérico, 3 vol. Madrid.

RUANo, E., en colaboración con M. R. LuCAS: Arte ibérico de piedra en la Provincia de Jaén (en prensa).

Ruiz, J., y CRuz, T., 1985: «Baeza en la Antigüedad. Sus origenes. Historia, Literarua, Arte" en Historia de Baeza, pág. 38 y ss.

Serrano, J., y Morena, J. A., 1989: “Un relieve de Baja Época Ibérica procedente de Torreparedones (Castro el Rio-Baena. Córdoba)", Bol. As. E.A. A., núm. 26, págs. 34-42 («Noticia en núm. 88 de A.E.A., en prensa).

SHILOH, Y., 1979: The proto-aeolic chapitel and Israelite Ashlar Masonery, Univ. de Jerusalen.

VV. AA., 1988: I Fenici, Milán.

WESENBERG, B., 1971: Kapitelle und Basen, Düsseldorf. 